\title{
Change in prevalence of gestational diabetes and obstetric complications when applying IADPSG screening criteria in a Belgian French speaking University Hospital. A retrospective cohort study
}

Elena Costa $^{1 *}$ (D), Christine Kirckpartick ${ }^{1}$, Colette Gerday ${ }^{1}$, Aricia De Kempeneer ${ }^{1}$, Sara Derisbourg ${ }^{1}$, An Vercoutere ${ }^{1}$, Sophie Haumont ${ }^{2}$, Axelle Pintiaux ${ }^{1}$ and Caroline Daelemans ${ }^{1}$

\begin{abstract}
Background: In April 2012 our institution chose to switch from a two- step criteria for Gestational Diabetes Mellitus (GDM) screening, to the International Association of Diabetes in Pregnancy Study Group (IADSPG) criteria. This shift led to an increased prevalence of GDM in our pregnant population. We designed a study in order to estimate the magnitude of the increase in GDM prevalence before and after the switch in screening strategy. As a secondary objective we wanted to evaluate if there was a significant difference between the two periods in the percentage of maternal and neonatal complications such as gestational hypertensive disorders (GHD), primary cesarean section (pCS), preterm birth, large for gestational age (LGA) newborns, macrosomia, shoulder dystocia, 5' Apgar score less than to 7 at birth, neonatal intensive care unit (NICU) transfer and neonatal hypoglycemia.

Methods: We selected retrospectively 3496 patients who delivered between January 2009 and December 2011 who were screened with the two-step criteria (group A), and compared them to 2555 patients who delivered between January 2013 and December 2014 and who were screened with IADPSG criteria (Group B). We checked patients' electronic files to establish GDM status, baseline characteristics (age, body mass index, nationality, parity) and the presence of maternal and neonatal complications.

Results: GDM prevalence increased significantly from group A $(3.4 \% ; 95 \% \mathrm{Cl} 2.8-4.06 \%)$ to group B $(16.28 \% ; 95 \% \mathrm{Cl}$ $14.8-17.7 \%)$. In group $B$ there were significantly more non-Belgian and primiparous patients. There was no statistically significant difference in maternal and neonatal complications between the two groups, even after adjustment for nationality and parity.

There was a non-significant reduction of the proportion of macrosomic and of LGA babies.

Conclusions: In our population the introduction of IADPSG screening criteria has increased the prevalence of GDM without having a statistically significant impact on pregnancy outcomes.
\end{abstract}

Keywords: Gestational diabetes Mellitus, IADPSG criteria, Two step criteria, Obstetric outcomes

\footnotetext{
* Correspondence: ecosta@ulb.ac.be

'Department of Obstetrics and Gynaecology, Hôpital Erasme, Route de

Lennik 808, 1070 Anderlecht, Belgium

Full list of author information is available at the end of the article
}

(c) The Author(s). 2019 Open Access This article is distributed under the terms of the Creative Commons Attribution 4.0 International License (http://creativecommons.org/licenses/by/4.0/) which permits unrestricted use, distribution, and reproduction in any medium, provided you give appropriate credit to the original author(s) and the source, provide a link to the Creative Commons license, and indicate if changes were made. The Creative Commons Public Domain Dedication waiver (http://creativecommons.org/publicdomain/zero/1.0/) applies to the data made available in this article, unless otherwise stated. 


\section{Background}

The World Health Organization (WHO) in 1999 has defined Gestational Diabetes Mellitus (GDM) as a carbohydrate intolerance resulting in hyperglycemia of variable severity, with onset or first recognition during pregnancy [1]. Extensive research has demonstrated that GDM is associated with short- and long-term complications concerning both mother and child. Screening and treating GDM are an effective means to prevent short term complications [2] and a significant opportunity for intervention in order to avoid long term ones [3] . Short term complications are related to excessive fetal size leading to increased risk of difficult labor and delivery [4-6] and to the occurrence of maternal hypertensive disorders [6]. Long term complications include maternal increased risk of developing type 2 diabetes (T2DM) later in life and major potential metabolic pattern disorders in the offspring, which would lead to an increased risk of abnormal glucose tolerance, obesity and metabolic syndrome [3]

The International Association of Diabetes in Pregnancy Study Group (IADPSG) in 2010, following the Hyperglycemia and Adverse Pregnancy Outcome (HAPO) Study [5], has set a strategy of GDM screening based on a universal one-step $75 \mathrm{~g}$ Oral Glucose Tolerance Test (OGTT) between 24 and 28 weeks of gestation (WG). This allowed identifying, on an arbitrary basis, an excess risk of $75 \%$ of neonatal weight, a concentration of C-Peptide in the umbilical cord and adiposity in the newborn, each or all above the 90th percentile.

Applying IADPSG criteria invariably increases the prevalence of GDM in a given population, since it includes milder cases of GDM [7-11].

Our institution, Hôpital Erasme, is the Academic Hospital of the Université Libre de Bruxelles (ULB), a tertiary referral center that serves mainly the southern boroughs of the city of Brussels and the Belgian province of Hainaut.

In our department we switched from a GDM screening strategy with two-step criteria $(50 \mathrm{~g}$ Glucose Challenge Test (GCT) followed, if positive, by $75 \mathrm{~g}$ OGTT [12]) to the one-step IADPSG criteria in 2012. The switch was made after the GGOLFB (Groupement des Gynécologues Obstétriciens de Langue Française de Belgique), the Belgian association of French speaking obstetricians and gynecologists, endorsed IADPSG criteria for GDM screening [13].

The primary objective of this study is to estimate the difference in prevalence of GDM in the pregnant population screened in our institution according to one-step and two-step strategies.

Our secondary objective is to compare the frequency of the subsequent maternal and neonatal outcomes that are usually associated with GDM, before and after we changed screening strategy, such as: Gestational Hypertensive Disorders (GHD), primary Cesarean Section (pCS), preterm birth, shoulder dystocia, macrosomia, Large for Gestational Age (LGA) newborns, Neonatal Intensive Care Unit (NICU) transfer and neonatal hypoglycemia.

\section{Methods}

We designed a retrospective cohort study. We included all patients who delivered in our institution between January 2009 and December 2011 (Group A) and all patients who delivered between January 2013 and December 2014 (Group B). Patients in Group A were screened with two-step criteria: they underwent a $50 \mathrm{~g}$ Glucose Challenge Test (GCT) at 24 WG, then in the case the GCT was equal or above $140 \mathrm{mg} / \mathrm{dl}$, the patients were tested with a $75 \mathrm{~g}$ Oral Glucose Tolerance Test (OGTT). They were considered positive if at least two out of three values were above the following thresholds: $95 \mathrm{mg} / \mathrm{dl}$ fasting, $180 \mathrm{mg} / \mathrm{dl}$ after $1 \mathrm{~h}, 155 \mathrm{mg} / \mathrm{dl}$ after two hours. Patients in Group B were screened using the one-step IADPSG criteria: they were given a Fasting Plasma Glucose test (FPG) at first visit, and diagnosed with GDM if it was equal to or greater than $92 \mathrm{mg} / \mathrm{dl}$. The patients who had a negative FPG were screened between 24 and 28 WG with a $75 \mathrm{~g}$ OGTT that was considered positive if at least one value exceeded the thresholds $(92 \mathrm{mg} / \mathrm{dl}$ fasting, $180 \mathrm{mg} / \mathrm{dl}$ at one hour, $153 \mathrm{mg} / \mathrm{dl}$ at two hours). We did not consider individuals who delivered in 2012, since this was a transition year in the screening strategy. We also excluded from analysis all patients who carried a multiple pregnancy. If the same patient delivered twice in the time frame defined by the study, we considered only the first delivery, in order to keep observations independent. We retrieved all data by extracting them from our electronic patient filing system. We excluded all patients for whom the results of the GDM screening test were not reported in the file. This included patients who were not screened in our institution (they were followed up in private practices and came to our institution only for delivery), patients who refused screening, patients who did not tolerate screening, and patients already followed up for pre-gestational diabetes.

In our institution all patients diagnosed with GDM were given dietary advice, taught to self-monitor glycaemia and were treated with medication if judged necessary by the endocrinologist. Glycemic targets were 95 $\mathrm{mg} / \mathrm{dl}$ fasting and $120 \mathrm{mg} / \mathrm{dl}$ at $2 \mathrm{~h}$ postprandial. In the periods included in our study, diabetological care was coordinated by the same endocrinologist and glycemic targets did not change.

For each subject, we collected the following baseline data: age (divided into four categories: $<18$ years, $18-29$ years, 30-39 years and $>39$ years), maternal pre- 
gestational Body Mass Index (BMI) (divided into four categories: underweight if $<18.5 \mathrm{Kg} / \mathrm{m}^{2}$, normal weight if $18.5-24.99 \mathrm{Kg} / \mathrm{m}^{2}$, overweight if $25-30 \mathrm{Kg} / \mathrm{m}^{2}$ and obese if $>30 \mathrm{Kg} / \mathrm{m}^{2}$ ), nationality at birth of the mother (divided into two categories: Belgian and non-Belgian), parity (divided into two categories: primiparous and multiparous) and previous CS (presence or absence of a cesarean section in the obstetric history of the multiparous patients). For each subject, we collected the following outcome variables: GDM screening results, presence of GHD (presence or absence of either gestational hypertension, preeclampsia or eclampsia), pCS (presence or absence of CS in the index pregnancy without previous history of CS), preterm birth (delivery before $37 \mathrm{WG}$ ), occurrence of shoulder dystocia (recording of one or more maneuvers aimed at resolving shoulder dystocia during delivery), macrosomia (presence or absence of newborn weight $>4000 \mathrm{~g}$ ), LGA newborns (presence or absence of newborn weight $>$ p90 for gestational age), 5' Apgar score (divided in two categories $>=7$ or $<7$ ), transfer to NICU (hospitalization of the newborn in the NICU for any amount of time), and neonatal hypoglycemia (glycemia in the cord blood of the newborn $<50 \mathrm{mg} / \mathrm{dl}$ ). We calculated percentiles of birth weight for newborns using AUDIPOG (Association des Utilisateurs de Dossiers Informatisés en Pédiatrie, Obstétrique et Gynécologie) curves [14]. Independently from the result of the screening test, the health practitioner had the possibility to flag the patient as affected by GDM.

This study has been approved by the independent ethics institutional review board (IRB) of Hôpital Erasme.

\section{Statistical analysis}

We compared baseline characteristics of the two cohorts using the chi squared test. We computed prevalence of GDM for the two groups and we assessed 95\% CI using the exact method [15]. We compared GDM prevalence and proportions of obstetrical complications using the chi squared test, then computed Odds Ratios (OR) and 95\% CI using a univariate logistic regression. We corrected the crude OR by baseline characteristics which had a difference in the two groups of a $p$-value of 0.2 or less, by multivariate logistic regression, producing adjusted OR (aOR) and 95\% CI.

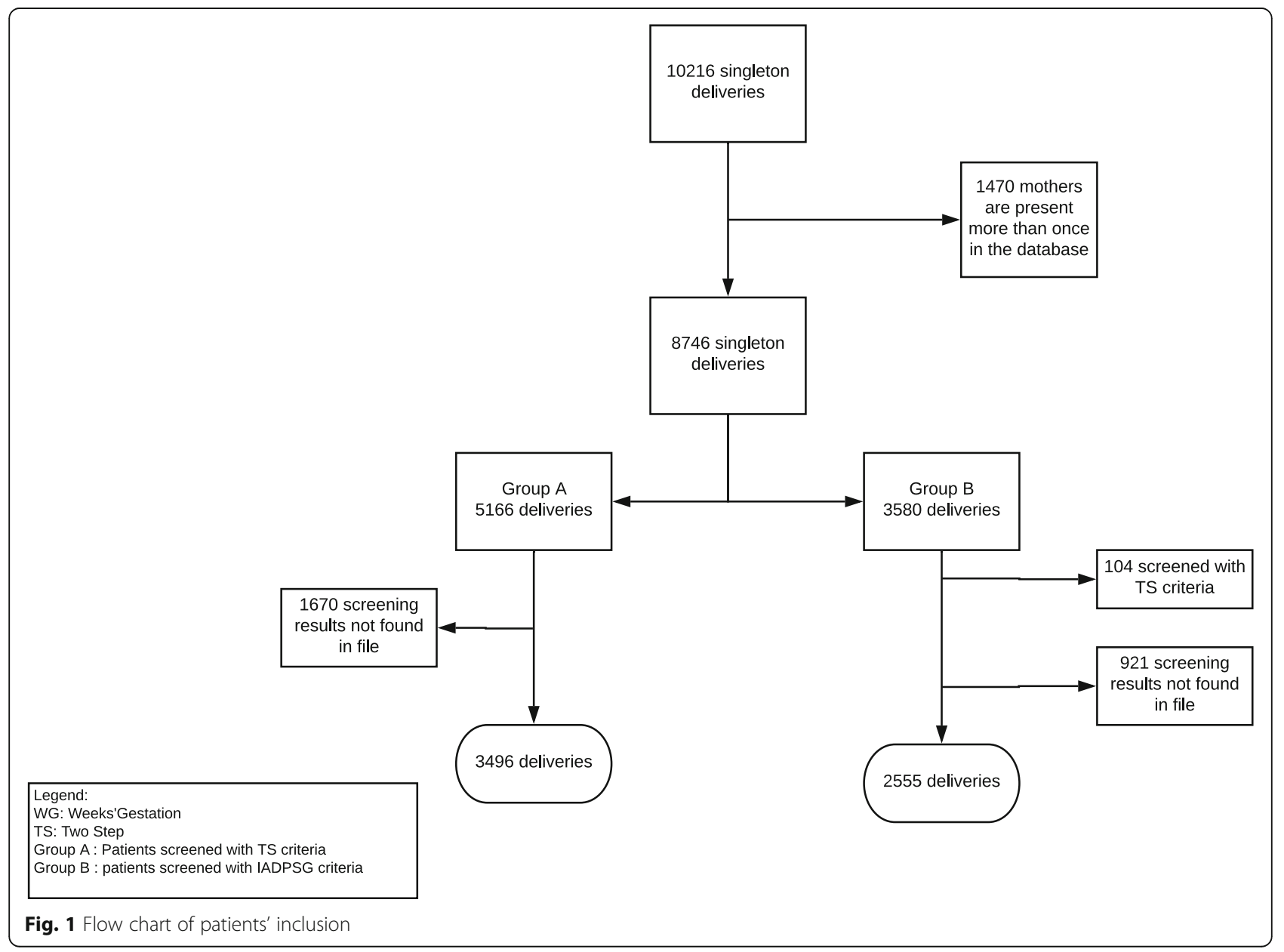


We considered statistically significant a two-tailed $p$ value inferior to 0.05 . We performed all statistical analysis using STATA 15 for Windows.

\section{Results}

We recruited 3496 subjects in Group A and 2555 subjects in Group B, the flow chart of patient selection is described in Fig. 1.

There was no statistically significant difference between the two groups in the distribution of maternal age and pre-gestational BMI. The proportion of Belgian patients was significantly higher in Group A (80.21\%) compared to Group B $(74.01 \%, p$-value $<0.01)$. The proportion of multiparous patients was also higher in Group A (57.29\%) compared to Group B $(51.55 \%, p$-value $<0.01)$. Table 1 illustrates baseline characteristics in the two groups.

In Group A, 119 out of 3496 tests were positive for GDM (3.4\%; 95\%CI 2.8-4.06\%), in Group B, 416 out of 2555 (16.3\%; 95\%CI 14.8 -17.7\%) which translates into an OR of $5.51(95 \% \mathrm{CI} 4.46-6.81, p$-value $<0.01)$. The difference in prevalence is illustrated in Fig. 2.

The proportion of LGA babies was lower in Group B (10.81\%; 95\%CI 9.6-12.1\%) compared to Group A (12.39\%; 95\%CI 11.3-13.5\%), as illustrated in Fig. 3, but the difference did not reach statistical significance ( $p$-value 0.059). The proportion of macrosomia was also nonstatistically significantly lower in Group B (7.75\%; 95\%CI $6.7-8.8 \%)$ compared to Group A $(9.12 \%$; $95 \%$ CI $8.2-$ 10.1\%; p-value 0.059), as can be seen in Fig. 4. With the exception of the prevalence of GDM, all the outcomes

Table 1 Baseline characteristics

\begin{tabular}{lllr}
\hline & Group A & Group B & $p$-value \\
\hline Age & $n=3496$ & $n=2555$ & 0.705 \\
$18-29$ & $14(0.4 \%)$ & $9(0.35 \%)$ & \\
$30-39$ & $1668(47.71 \%)$ & $1184(46.34 \%)$ & \\
$>39$ & $1640(46.91 \%)$ & $1237(48.41 \%)$ & \\
Maternal BMI & $174(4.98 \%)$ & $125(4.89 \%)$ & \\
Underweight & $n=2908$ & $n=2005$ & 0.438 \\
Normal Weight & $126(4.33 \%)$ & $77(3.84 \%)$ & \\
Overweight & $1660(57.08 \%)$ & $1134(56.87 \%)$ & \\
Obese & $385(13.25 .34 \%)$ & $499(24.89 \%)$ & \\
Nationality & $\mathrm{n}=3496$ & $295(14.71 \%)$ & \\
Belgian & $2804(80.21 \%)$ & $1891(74.01 \%)$ & \\
$\quad$ Non-Belgian & $692(19.79 \%)$ & $664(25.99 \%)$ & \\
Parity & $\mathrm{n}=3496$ & $\mathrm{n}=2555$ & $<0.01$ \\
Primiparous & $1493(42.71 \%)$ & $1238(48.45 \%$ & \\
Multiparous & $2003(57.29 \%)$ & $1317(51.55 \%)$ & \\
\hline
\end{tabular}

${ }^{a}$ Missing values maternal BMI $16.7 \%$, randomly distributed in age, nationality, parity and GDM analyzed (LGA, macrosomia, 5'Apgar score, GHD, preterm birth, pCS, transfer to NICU and neonatal hypoglycemia) did not differ significantly between the two groups, even after adjustment for potential confounders (nationality and parity). Table 2 illustrates the details of maternal and neonatal outcomes in the two groups.

\section{Discussion}

To our knowledge, this is the first study in Europe that compares the prevalence of GDM obtained with the IADPSG one-step criteria to the prevalence obtained with the two-step approach as recommended by the American Diabetes Association (ADA) in 2003 (defined as a $50 \mathrm{~g}$ CGT followed by a $75 \mathrm{~g}$ OGTT), instead of the classical Carpenter an Coustan (CC) criteria (where the GCT is followed by a $100 \mathrm{~g}$ OGTT [16]).

In our study we have observed that, once our institution introduced IADPSG criteria, the prevalence of GDM increased dramatically from 3.4 to $16.3 \%$, which translated into an OR of 5.51. The OR did not vary in a meaningful way even after we took into consideration and corrected for the evolution of the characteristics in our population, which showed a significant increase of the proportion of primiparous and foreign patients. The observed GDM prevalence in Group B was similar to the one reported in the original HAPO study cohort [5].

This increase of GDM prevalence when shifting from two-step to IADPSG criteria has been consistently reported across studies, since IADPSG criteria are designed to identify milder cases of GDM. The magnitude of the increase varies in different reports $[7-11,17]$. One randomized controlled trial showed a nonstatistically significant difference in the prevalence of GDM [18], but it was probably due to the small sample size.

We expected a higher rate of GDM in Group A, similar to those reported by other authors who investigated GDM prevalence in the Belgian French-speaking Community, which varied from 5.2\% [19] to 8\% [11]. However, in both publications, the two-step GDM screening was done with classical Carpenter and Coustan criteria, which indicates that screening with a $75 \mathrm{~g}$ diagnostic OGTT might have been even more restrictive in the diagnosis of GDM than with a $100 \mathrm{~g}$ OGTT.

In our methodology, we chose to calculate GDM prevalence only on the analysis of the screening tests that we could retrieve, and not on the flagging of a patient as GDM in the patient's file. The rationale for this decision was that we feared underreporting of GDM, since the flagging was possible but not compulsory. Surprisingly, we observed that in group A flagged GDM patients were $5.53 \%$ (data not shown). This phenomenon has been also described by Kong et al. [10] where they assumed that women screened with Carpenter and 


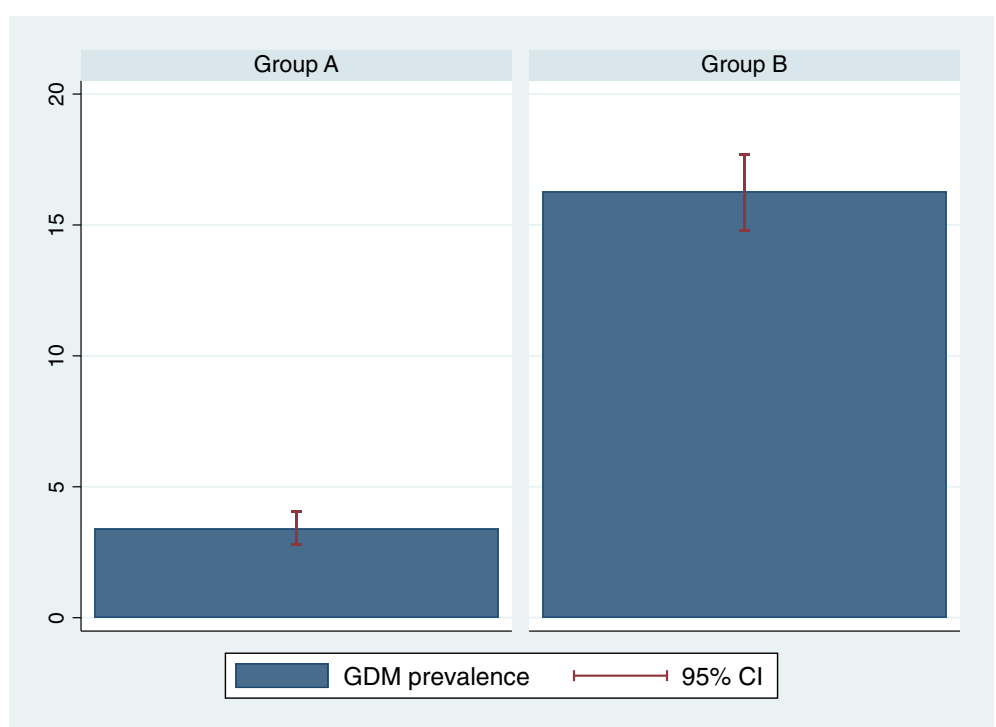

Fig. 2 Prevalence of GDM patients in Group A and B

Coustan criteria with borderline results might have been flagged as GDM.

The advantage of introducing the IADPSG criteria is that we expect a reduction, in the screened population, of obstetric adverse outcomes such as GHD, macrosomia, LGA newborns, and potentially a lower rate of CS and shoulder dystocia.

A secondary analysis of the HAPO study [20] concerning untreated participants in North America demonstrated that the extra women who were classified as GDM by IADPSG criteria, had worse neonatal outcomes than those who were screened negative (and better outcomes than those who were screened positive by $\mathrm{CC}$ criteria). This was observed for the outcomes related to adiposity of the newborn (evaluated by macrosomia and LGA), but also for GHD.

This secondary analysis confirmed the argument underlying the HAPO study, namely that GDM-linked obstetric complications correlate in a continuous fashion with levels of glycaemia [5] - but it didn't say if screening and treating milder cases of GDM improve overall outcomes.

Although theoretically treating milder cases of GDM should lead to better obstetric outcomes [20-23], there

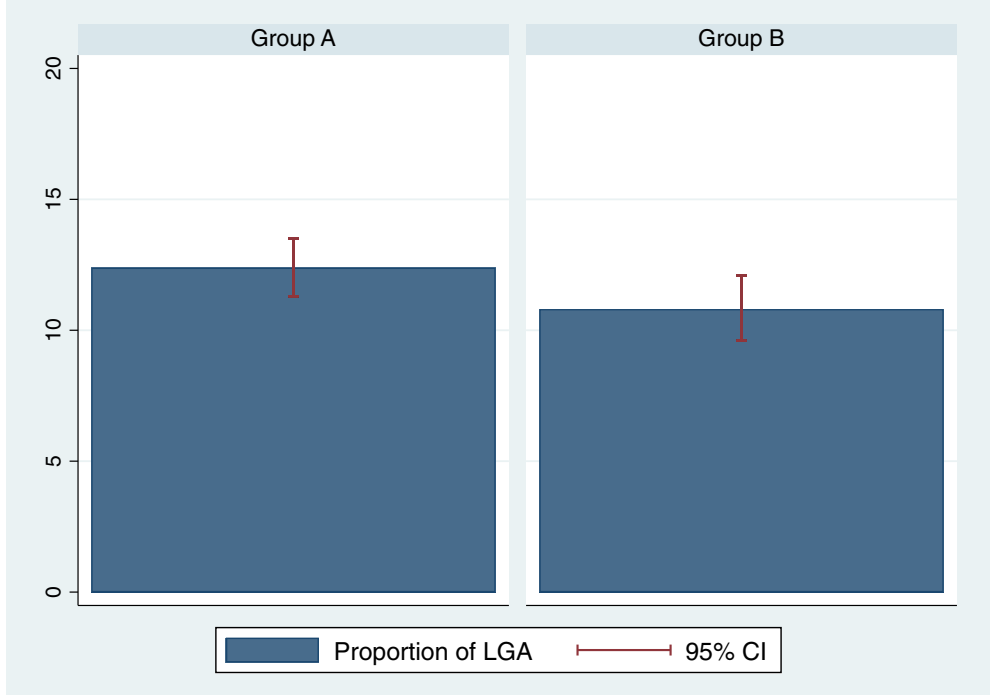

Fig. 3 Prevalence of LGA newborns in Group A and B 


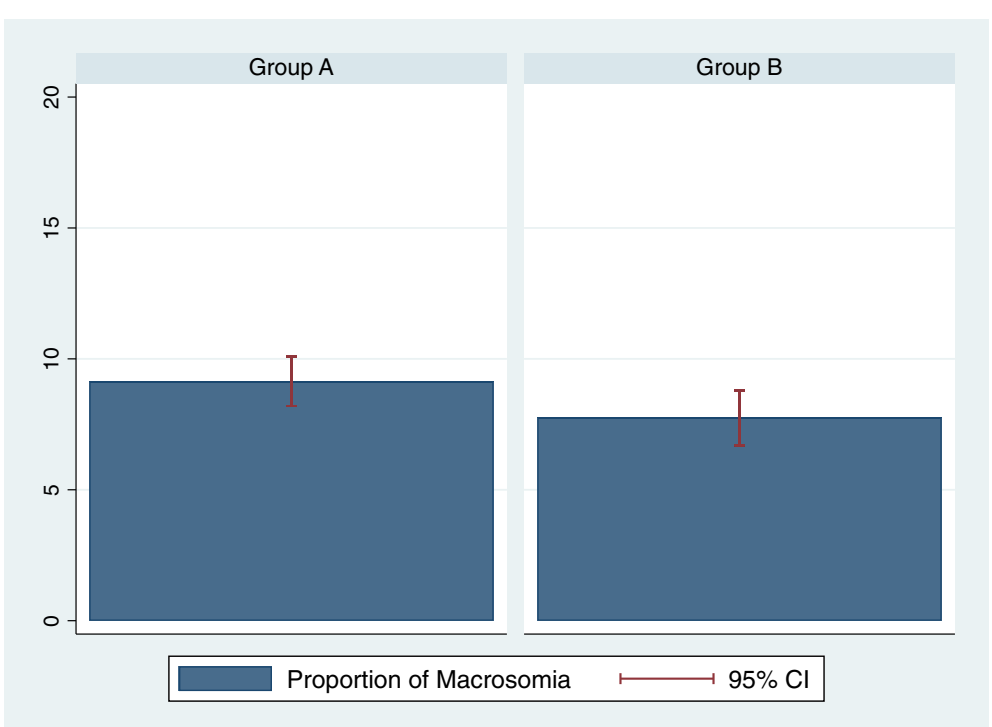

Fig. 4 Prevalence of macrosomia in Group A and B

is yet no conclusive evidence that this improvement exists when applying the criteria in real-life clinical settings.

In our cohort, even if we diagnosed almost five times more cases of GDM using the IADPSG criteria, and therefore the impact on outcomes should be relevant, the prevalence of obstetric complications most frequently linked to GDM appeared to remain stable. There was however a decrease in the proportion of macrosomia and LGA babies, which fell short of statistical significance.

Table 2 Maternal and neonatal outcomes according to the two screening strategies

\begin{tabular}{|c|c|c|c|c|c|}
\hline & Group A & Group B & OR $(95 \% \mathrm{Cl})$ & $p$-value & $\mathrm{aOR}(95 \% \mathrm{Cl})^{\mathrm{a}}$ \\
\hline \multirow[t]{2}{*}{ Gestational Diabetes Mellitus } & $n=3496$ & $n=2555$ & & & \\
\hline & 119 (3.4\%) & $416(16.28 \%)$ & $5.51(4.46-6.81)$ & $<0.001$ & $5.53(4.48-6.84)$ \\
\hline \multirow[t]{2}{*}{ Primary Cesarean section } & $n=3135$ & $n=2321$ & & & \\
\hline & $386(12.31 \%)$ & $320(13.79 \%)$ & $1.13(0.97-1.33)$ & 0.109 & $1.07(0.91-1.26)$ \\
\hline \multirow[t]{2}{*}{ Gestational hypertensive disorders } & $n=3496$ & $n=2555$ & & & \\
\hline & $101(2.89 \%)$ & $73(2.86 \%)$ & $0.98(0.72-1.34)$ & 0.942 & $0.93(0.69-1.27)$ \\
\hline \multirow[t]{2}{*}{ Preterm birth } & $n=3496$ & $n=2555$ & & & \\
\hline & $228(6.52 \%)$ & $162(6.43 \%)$ & $0.97(0.78-1.19)$ & 0.777 & $0.97(0.79-1.2)$ \\
\hline \multirow[t]{2}{*}{ 5' Apgar score $<7$} & $n=3489$ & $n=2547$ & & & \\
\hline & $76(2.18 \%)$ & $56(2.2 \%)$ & $1.009(0.71-1.43)$ & 0.957 & $0.98(0.69-1.40)$ \\
\hline \multirow[t]{2}{*}{ Transfer to NICU } & $n=3404$ & $n=2547$ & & & \\
\hline & $277(8.14 \%)$ & $208(8.17 \%)$ & $1.003(0.83-1.21)$ & 0.968 & $0.97(0.81-1.18)$ \\
\hline \multirow[t]{2}{*}{ Neonatal hypoglycaemia } & $n=392$ & $n=438$ & & & \\
\hline & $65(16.58 \%)$ & $90(20.55 \%)$ & $1.3(0.91-1.85)$ & 0.144 & $1.37(0.96-1.97)$ \\
\hline \multirow[t]{2}{*}{ Shoulder dystocia } & $n=3489$ & $n=2547$ & & & \\
\hline & 64 (1.83\%) & $56(2.20 \%)$ & $1.2(0.83-1.72)$ & 0.317 & $1.19(0.83-1.72)$ \\
\hline \multirow[t]{2}{*}{ LGA } & $n=3496$ & $n=2555$ & & & \\
\hline & 433 (12.39\%) & 276 (10.81\%) & $0.85(0.73-1.006)$ & 0.059 & $0.87(0.74-1.03)$ \\
\hline \multirow[t]{2}{*}{ Macrosomia } & $n=3496$ & $n=2555$ & & & \\
\hline & 319 (9.12\%) & $198(7.75 \%)$ & $0.83(0.69-1.006)$ & 0.059 & $0.85(0.71-1.03)$ \\
\hline
\end{tabular}


Similar results were seen in other retrospective studies $[7,8,10]$, in particular the one by Ortio et al., where GDM prevalence went from 8 to $23 \%$ [11].

In contrast, a significant decrease of poor pregnancy outcomes (among which gestational hypertension and LGA) has been observed after diabetological care of the extra women classified as GDM by IADPSG criteria [9] . It is interesting to notice that in the article by Duran et al. [9], the glycemic target towards which GDM patients were educated was a fasting glucose level $<90 \mathrm{mg} / \mathrm{dl}$ and a $1 \mathrm{~h}$ post-meal glucose $<120 \mathrm{mg} / \mathrm{dl}$, which is lower than the recommended thresholds in our population.

It is important to note that, to this day, an adequately powered prospective randomized trial comparing maternal and neonatal outcomes in pregnancies screened with the CC and the IADPSG criteria, has not been carried out.

Moreover, the increase in prevalence that occurs after the implementation of the IADPSG screening strategy is bound to put a strain in the pathway of care of GDM positive patients, and may lead to a potential overmedicalization of such pregnancies. This is why the cost effectiveness of the IADPSG screening strategy is still object of debate [24].

In our view, even if applying the IADPSG criteria should decrease obstetric complications linked to GDM, the number needed to screen in order to detect a positive result in maternal and neonatal outcomes may be high.

The decrease in obstetric complications, though, depends on many variables other than the screening strategy alone. These variables include screening and treatment acceptability by patients [25], glycemic targets, adherence to treatment, and the independent influence of maternal BMI [6]. The strength of obstetrics and endocrinological care coordination might also have to be explored carefully.

This study has several limitations: there was a significant proportion of patients who delivered at Erasme hospital for whom we could not retrieve GDM screening results in our files (32\% in group A and $24 \%$ in group B), and this could have had an impact on our estimate of GDM prevalence in the population delivering in our hospital. Nonetheless we observed that the majority of individuals for whom we have no results are those who were followed up in private practices and came to Erasme only for delivery. In this case we could say that the reported GDM prevalence is that of patients that are routinely followed up at Erasme.

Another limitation is the retrospective nature of our study, which means that there are many variables that we could not control for. In particular, we could not control for how the adherence to treatment has changed in the two time periods. This potential bias would have been interesting to factor in since the increase of GDM prevalence following the switch in screening strategy has surely put a burden on the pathway of care for GDM positive patients. In addition to that, our data on the history of GDM for multiparous patients and for family history of T2DM were not reliable and were, therefore, not reported. We cannot exclude the role of these potential confounding factors in the evolution of the prevalence of GDM in our population.

We conclude that in our population, with the current care for GDM positive patients, screening and treating milder cases of GDM does not seem to translate into improved obstetric outcomes. We do observe, though, a tendency to a smaller proportion of LGA babies and macrosomia in the group screened with IADPSG criteria.

Further research will have to be carried out, in particular an adequately powered prospective experimental study is needed to establish if applying the IADPSG criteria decreases the frequency of adverse obstetric outcomes.

\section{Conclusions}

In our population the introduction of IADPSG screening criteria has increased the prevalence of GDM without having a statistically significant impact on pregnancy outcomes. We observe a non-statistically significant decrease in LGA babies and macrosomia.

\section{Abbreviations}

ADA: American Diabetes Association; AUDIPOG: Association des Utilisateurs de Dossier Informatisés en Pédiatrie, Obstetrique et; BMI: Body Mass Index; CC: Carpenter and Coustan; CS: Cesarean Section; FPG: Fasting Plasma Glucose; GCT: Glucose Challenge Test; GDM: Gestational Diabetes Mellitus; GHD: Gestational Hypertensive Disorders Gynécologie; HAPO: Hyperglycemia and Adverse Pregnancy Outcome; IADPSG: International Association of Diabetes in Pregnancy Study Group; LGA: Large for Gestational Age; NICU: Neonatal Intensive Care Unit; OGTT: Oral Glucose Tolerance Test; OR: Odds Ratio; pCS: primary Cesarean Section; T2DM: Type 2 Diabetes Mellitus; ULB: Université Libre de Bruxelles; WG: Weeks Gestation

\section{Acknowledgements}

We acknowledge Fonds Erasme pour la recherche médicale for supporting young researchers in our institution. In addition, we acknowledge Dr. Arianna Keramyda and Prof Ira M. Sohn for their help in reviewing the manuscript for issues related to English grammar and word usage. We would also like to aknowledge Mr. Michael Blanga-Gubbay for his help in designing the figures.

\section{Authors' contributions}

EC was responsible for the study design, data collection, data analysis and redaction of the manuscript. CK was responsible for obstetrical follow up of GDM patients during the study period, and was responsible of the

conception of the study. CG was a key contributor in the study design, gave her critical insight on data collection. ADK was responsible for data collection and gave determinant insight in data analysis. SD contributed to data analysis and redaction of the manuscript. AV contributed to data analysis and redaction of the manuscript. SH was responsible for the endocrinological follow up of GDM patients during the study period and gave essential input in the study design. AP and CD were actively involved in the study design and gave critical insight on data analysis. All authors read, substantially collaborated in drafting the manuscript and approved the manuscript. 


\section{Funding}

This research has been carried out with the support of Fonds Erasme pour la recherche médicale, which founded $50 \%$ of the first author's salary. The funding body had no role whatsoever in the design of the study, collection, analysis, and interpretation of data and in writing the manuscript.

\section{Availability of data and materials}

The datasets used and analysed during the current study are available from the corresponding author on reasonable request.

\section{Ethics approval and consent to participate}

This study has been approved by the ethical committee of Erasme Hospital, approval number 021/406. Consent to participate was waived due to the retrospective nature of the study.

\section{Consent for publication}

Not applicable.

\section{Competing interests}

The authors declare that they have no competing interests.

\section{Author details}

${ }^{1}$ Department of Obstetrics and Gynaecology, Hôpital Erasme, Route de Lennik 808, 1070 Anderlecht, Belgium. ${ }^{2}$ Department of Endocrinology, Hôpital Erasme, Route de Lennik 808, 1070 Anderlecht, Belgium.

Received: 14 April 2019 Accepted: 10 July 2019

Published online: 16 July 2019

\section{References}

1. Alberti KG, Zimmet PZ. Definition, diagnosis and classification of diabetes mellitus and its complications. Part 1: diagnosis and classification of diabetes mellitus provisional report of a WHO consultation. Diabet Med. 1998:15(7):539-53.

2. Crowther CA, Hiller JE, Moss JR, McPhee AJ, Jeffries WS, Robinson JS, Group ACISiPWAT. Effect of treatment of gestational diabetes mellitus on pregnancy outcomes. N Engl J Med. 2005;352(24):2477-86.

3. Damm P. Future risk of diabetes in mother and child after gestational diabetes mellitus. Int J Gynaecol Obstet. 2009;104(Suppl 1):S25-6.

4. Casey BM, Lucas MJ, Mcintire DD, Leveno KJ. Pregnancy outcomes in women with gestational diabetes compared with the general obstetric population. Obstet Gynecol. 1997;90(6):869-73.

5. Metzger BE, Lowe LP, Dyer AR, Trimble ER, Chaovarindr U, Coustan DR, Hadden DR, McCance DR, Hod M, McIntyre HD, et al. Hyperglycemia and adverse pregnancy outcomes. N Engl J Med. 2008:358(19):1991-2002.

6. Catalano PM, McIntyre HD, Cruickshank JK, McCance DR, Dyer AR, Metzger BE, Lowe LP, Trimble ER, Coustan DR, Hadden DR, et al. The hyperglycemia and adverse pregnancy outcome study: associations of GDM and obesity with pregnancy outcomes. Diabetes Care. 2012;35(4):780-6.

7. Feldman RK, Tieu RS, Yasumura L. Gestational diabetes screening: the International Association of the Diabetes and Pregnancy Study Groups Compared with Carpenter-Coustan Screening. Obstet Gynecol. 2016;127(1): 10-7.

8. Gerome JM, Bucher LKM, Dogbey G. Effects of implementing International Association of Diabetes and Pregnancy Study Groups Gestational Diabetes Screening on pregnancy outcomes at a small community teaching hospital. Clin Diabetes. 2017;35(2):84-9.

9. Duran A, Sáenz S, Torrejón MJ, Bordiú E, Del Valle L, Galindo M, Perez N, Herraiz MA, Izquierdo N, Rubio MA, et al. Introduction of IADPSG criteria for the screening and diagnosis of gestational diabetes mellitus results in improved pregnancy outcomes at a lower cost in a large cohort of pregnant women: the St. Carlos gestational diabetes study. Diabetes Care. 2014;37(9):2442-50.

10. Kong JM, Lim K, Thompson DM. Evaluation of the International Association of the Diabetes in Pregnancy Study Group new criteria: gestational diabetes project. Can J Diabetes. 2015;39(2):128-32.

11. Oriot P, Selvais P, Radikov J, Jacobs JL, Gilleman U, Loumaye R, Fernandez C Assessing the incidence of gestational diabetes and neonatal outcomes using the IADPSG guidelines in comparison with the carpenter and Coustan criteria in a Belgian general hospital. Acta Clin Belg. 2014;69(1):8-11.
12. Metzger BE, Coustan DR. Summary and recommendations of the fourth international workshop-conference on gestational diabetes Mellitus. The organizing committee. Diabetes Care. 1998;21(Suppl 2):B161-7.

13. Vanderijst J, Debieve F, Ducet $F$, Emonts $P$, et al. e dépistage et critères diagnostiques du diabète gestationnel. Propositions du GGOLFB. Rev Med Brux. 2012;33:97-104.

14. Neonatal morphometric curves - AUDIPOG [http://www.audipog.net/ courbes_morpho.php].

15. Clopper C, Pearson ES. The use of confidence or fiducial limits illustrated in the case of the binomial. Biometrika. 1934;26:404-13.

16. Mellitus ECotDaCoD. Report of the expert committee on the diagnosis and classification of diabetes mellitus. Diabetes Care. 2003;26(Suppl 1):S5-20.

17. Benhalima K, Hanssens M, Devlieger R, Verhaeghe J, Mathieu C. Analysis of pregnancy outcomes using the new IADPSG recommendation compared with the carpenter and Coustan criteria in an area with a low prevalence of gestational diabetes. Int J Endocrinol. 2013;2013:248121.

18. Khalifeh A, Eckler R, Felder L, Saccone G, Caissutti C, Berghella V. One-step versus two-step diagnostic testing for gestational diabetes: a randomized controlled trial. J Matern Fetal Neonatal Med. 2018;13:1-6.

19. Minsart AF, Lescrainier JP, Vokaer A. Selective versus universal screening for gestational diabetes mellitus: an evaluation of Naylor's model. Gynecol Obstet Investig. 2009:68(3):154-9.

20. Waters TP, Dyer AR, Scholtens DM, Dooley SL, Herer E, Lowe LP, Oats JJ, Persson B, Sacks DA, Metzger BE, et al. Maternal and neonatal morbidity for women who would be added to the diagnosis of GDM using IADPSG criteria: a secondary analysis of the hyperglycemia and adverse pregnancy outcome study. Diabetes Care. 2016;39(12):2204-10.

21. Lindqvist $M$, Persson $M$, Lindkvist $M$, Mogren I. No consensus on gestational diabetes mellitus screening regimes in Sweden: pregnancy outcomes in relation to different screening regimes 2011 to 2012, a cross-sectional study. BMC Pregnancy Childbirth. 2014;14:185.

22. Mayo K, Melamed N, Vandenberghe $H$, Berger $H$. The impact of adoption of the international association of diabetes in pregnancy study group criteria for the screening and diagnosis of gestational diabetes. Am J Obstet Gynecol. 2015;212(2):224.e221-9.

23. Organization WH: WHO | Diagnostic criteria and classification of hyperglycaemia first detected in pregnancy. WHO 2013

24. Weile LK, Kahn JG, Marseille E, Jensen DM, Damm P, Lohse N. Global costeffectiveness of GDM screening and management: current knowledge and future needs. Best Pract Res Clin Obstet Gynaecol. 2015;29(2):206-24.

25. Parsons J, Sparrow K, Ismail K, Hunt K, Rogers H, Forbes A. Experiences of gestational diabetes and gestational diabetes care: a focus group and interview study. BMC Pregnancy Childbirth. 2018;18(1):25.

\section{Publisher's Note}

Springer Nature remains neutral with regard to jurisdictional claims in published maps and institutional affiliations.

Ready to submit your research? Choose BMC and benefit from:

- fast, convenient online submission

- thorough peer review by experienced researchers in your field

- rapid publication on acceptance

- support for research data, including large and complex data types

- gold Open Access which fosters wider collaboration and increased citations

- maximum visibility for your research: over $100 \mathrm{M}$ website views per year

At $\mathrm{BMC}$, research is always in progress.

Learn more biomedcentral.com/submissions 